\title{
REVIEW
}

\section{How to Integrate Ideological and Political Education into Mathematics Course of Vocational Education}

\section{Guijuan Tian*}

Taishan Campus, Shandong Transport Vocational College, Tai'an, Shandong, 271000, China

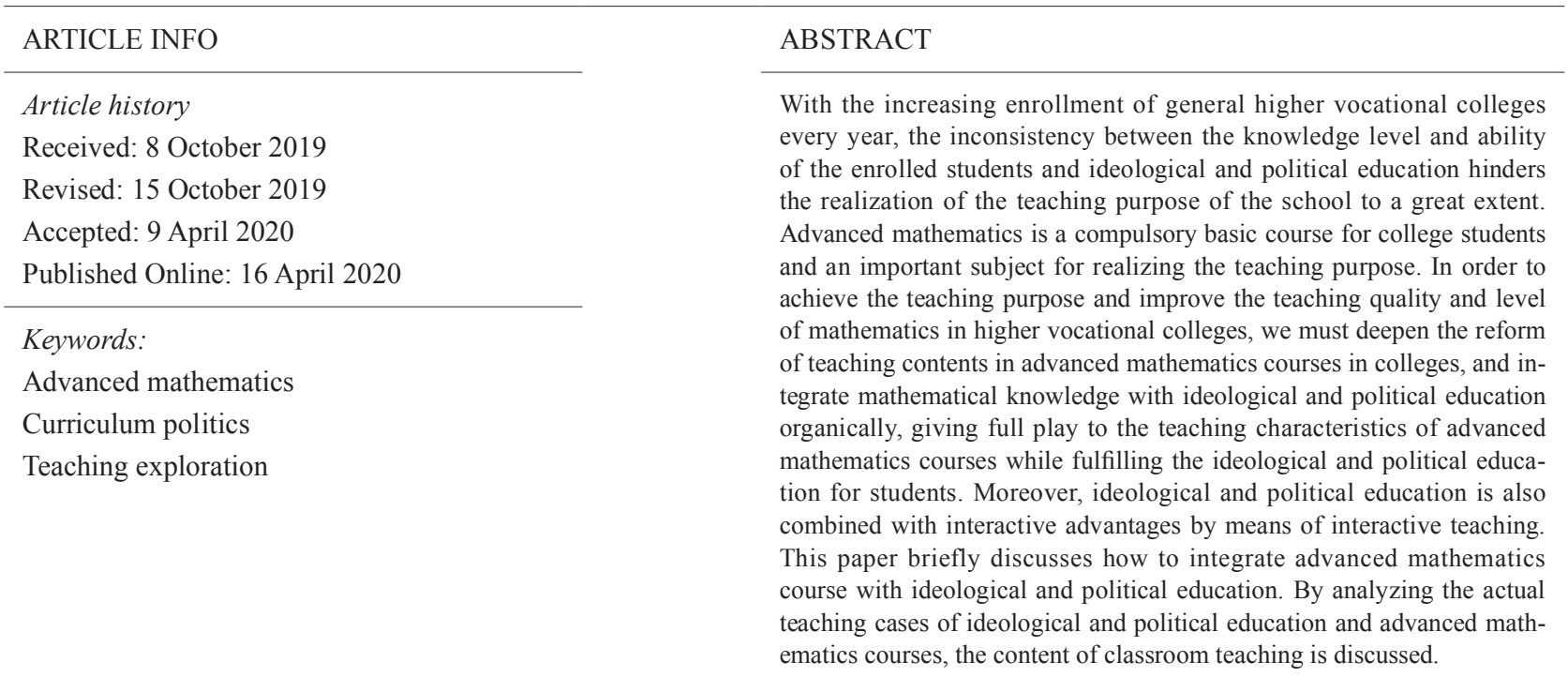

\section{What Is the Ideological and Political Edu-} cation in Advanced Mathematics Course

I $t$ is explained through the exploration of the "curriculum ideology and politics" concept in relevant colleges and universities in Shanghai. In order to solve and reduce the separation between the ideological and political education of college students and other courses they have learned, and to eliminate the differences between the two in students' actual courses, some schools have adopted the following methods to carry out relevant exploration: to make all of the ideological and political education functions contained in all courses completely applied in the students' course learning, while giving lectures, efforts should be made in the development and utilization of ideological and political education resources. As a result, ideological education is completed while learning a course, students' political education is enhanced while learning scientific knowledge, the teaching situation is more comprehensive and the educating result is deepened step by step.

With economic globalization, cultural diversity and the development of the trend of information network, as well as the transformation of society and the change of the education system and the employment system, new requirements are put forward for current higher vocational

*Corresponding Author:

Guijuan Tian,

Taishan Campus, Shandong Transport Vocational College, Tai'an, Shandong, 271000, China;

E-mail: tsxq_tianguijuan@163.com. 
student's quality, age, mentality and training purposes. The original management pattern in higher vocational colleges and simple imitation pattern of colleges and universities cannot satisfy the present social development. Meanwhile, the substandard ideological and political work of higher vocational college, and inconsistent goals of the education team result in the poor teaching effect of ideological and political courses, making the ideological and political education in higher vocational colleges further weakening, and ending up with some higher vocational students' world outlook, values, outlook on life appearing deviation with frequent psychological problems and prominent contradictions.

While ideology is the road sign of action, ideological and political course is the curriculum system of ideological and political theory education, and curriculum ideology and politics is the teaching system ${ }^{[3]}$. Therefore, ideological education and thought guidance have an important impact on students' action, and inadequate and unvalued particularity of ideological and political education in higher vocational colleges lead to loopholes and even mistakes in the practice of ideological and political work. Due to the influence of the current social problems, the ideological and political work in higher vocational colleges is becoming more and more complex, and the problems in the ideological and political work are also increasingly prominent. Hence, only by accurately grasping the new changes of educational objects, can the ideological and political education work of higher vocational college students be better done, so as to make the ideological and political education more pertinent, effective and appealing, and students' ideological quality and moral cultivation higher.

"Curriculum ideology and politics" refers to the inherent quality of ideological and political education contained in the course of teaching activities. "Curriculum ideology and politics" requires college teachers to pay attention to the process of teaching courses, and on the basis of guiding students to learn knowledge, to integrate the knowledge into their inherent virtues. The main body of "curriculum ideology and politics" is the teachers of all courses in colleges and universities, while "curriculum ideology and politics" is the moral practice in the process of teaching activities. By guiding students to integrate their learning into their own internal and transform into their own spirit, quality and ability in the process of teaching, they can make what they have learnt their basic ability and approach to understand and transform the world.

The meaning of "curriculum ideology and politics" refers to the new ideological and political work concept, focusing on the knowledge in the spread of cohesive value. "Curriculum ideology and politics" means "course bearing ideology and politics" and "ideology and politics embedded in course", emphasizing the value of leading knowledge dissemination, as well as the organic unity of classroom teaching, social practice and Internet ${ }^{[4]}$. Therefore, the essence of "curriculum ideology and politics" is to integrate ideological and political education into all aspects of curriculum teaching and reform in order to achieve the effect of imperceptibly and silently moistening things of ideological and political education without adding a course or an activity ${ }^{[5]}$.

The Outline of Implementing the Project of Improving the Quality of Ideological and Political Work in Colleges and Universities issued by the Ministry of Education in December 2017 points out that the goal of classroom teaching reform in colleges and universities should be to promote "curriculum ideology and politics". The whole process of higher education is the whole process of ideological and political education. The two are inseparable, and the teaching content of various courses and the ideological and political education in colleges and universities should be integrated organically and involved in classroom teaching. "Curriculum ideology and politics" should be based on the foundation of the development of discipline and specialty. The entry dimension of ideology and politics is to educate people, and ideological and political education involves the course itself. The ideological and political education resources of various courses should be given full play, so as to make "ideology and politics" and the courses inseparable from each other, to prepare for improving students' ideological level, political consciousness, moral quality and cultural accomplishment, and to realize the new idea and mode of ideological and political work in colleges and universities ${ }^{[6]}$.

\section{The Position of Ideological and Political Education in Advanced Mathematics Course}

The teaching content of advanced mathematics in higher vocational colleges has two main characteristics: commensurability and universality based on rules and laws, and emphasis on "skills" over "education" in mathematics teaching.

\subsection{Commensurability and Universality Based on Rules and Laws}

Commensurability and universality based on rules and laws of advanced mathematics is demonstrated in the course itself. Because advanced mathematics studies the truth and reality, without many restrictions to ideology and individual ideological or political position, it remains some difficulties to involve advanced mathematics course 
in the "curriculum ideology and politics" teaching reform. On the other hand, because the objects revealed by mathematics are real and universal, the philosophical thought represented by the law is also universal to some extent. Therefore, it has important positive guidance to the shaping of students' outlook on life and encourages students to develop more rationally.

\subsection{Emphasis on "Skills" over "Education" in Mathematics Teaching}

The reason why mathematics teaching emphasizes "skills" over "education" lies in the fact that mathematics learning clearly requires students to master basic mathematical concepts, theories, operation methods and skills, and pays attention to students' learning and accepting knowledge. So, in the teaching process, most teachers of advanced mathematics tend to attach more importance to tools while giving less curriculum content to morality cultivation. With the development of society and the change of social demand for talents, the enrollment system of colleges and universities has been making continuous reform and progress in recent years, and the enrollment structure and the changing trend of cultural foundation level and quantity has become increasingly diversified. At the same time, in the practice of mathematics teaching, projects of overall improving students' comprehensive ideological and political quality is far from enough.

\subsection{The Position of Ideological and Political Edu- cation in Advanced Mathematics Course}

Combining the teaching characteristics of advanced mathematics education with the above two points, the author believes that the effect of "Ideological and Political Education in Advanced Mathematics Course" is closely related to the implementation of ideological and political education. Only when the ideological and political education in advanced mathematics is put into practice can the educational function of advanced mathematics be brought into full play. In this way, students' learning can be transformed into their inner spirit, so that their mathematical thinking ability and ideological and political quality can go hand in hand and improve together. "Ideological and Political Education in Advanced Mathematics Course" should be positioned as a comprehensive exploration of the curriculum, exploring the integration of mathematical culture and higher education ideas into socialist ideology and culture, so that students can study pertinently according to practical problems in social development, and ultimately realize effective promotion of personal ideological and political quality in the process of solving practical problems.

\section{How to Do Ideological and Political Work of Advanced Mathematics Course Well in Colleges and Universities}

Mathematics is a typical natural science course which embodies the integration of scientific spirit and humanistic spirit and carries ideological and political education. To achieve the integration of scientific spirit and humanistic spirit, teachers of advanced mathematics should pay attention to combining the theoretical concepts and related calculation formulas with the ideological and political ideas contained in mathematics curriculum, fully excavating the education elements of "curriculum ideology and politics" in mathematics course, and integrating them into the actual mathematics classroom teaching.

In order to do the ideological and political work in advanced mathematics course well, we should first do the following two points: First, although the ideological and political education in advanced mathematics does not pursue strict logic and integrity, the course content must contain affinity and pertinence. Therefore, in the "curriculum ideology and politics" of advanced mathematics course, we should ensure that the class content is not boring theoretical education, giving students a feeling of ideological and political theory course. In addition, we should also pay attention to avoiding rigorous and cumbersome symbolic operation. Second, we should ensure rich and diverse ideological and political content and avoid empty and single content. Ideological and political education in advanced mathematics is not only a traditional course of ideological and political education and advanced mathematics, but also a course of values and morals of life, and a course of development history of mathematics. In order to do the ideological and political work of advanced mathematics course well, combining with the characteristics of advanced mathematics and students, the curriculum ideology and politics can be conducted in the following aspects:

(1) Based on the development of the industry of this major in China, and cooperated with multimedia content, we are to increase students' interest in learning and sense of identity, enhance their attention and sense of responsibility to the specialized courses, and contribute to the future career development of this major in China.

(2) Starting from the mathematical development history inheritance in China, this paper tries to arouse students' national pride and their attention to traditional culture through the long history of mathematics development in China. 
(3) We can take the inspirational stories of typical mathematicians in Chinese history as the starting points. For example, we can download videos about the legendary life experience of Hua Luogeng, Chinese master of mathematics, from the Internet for students, to inspire the students and make them understand the importance of diligence and striving for excellence, so as to cultivate their hardworking and innovative craftsmen spirit.

With the help of Internet video downloaded and broadcasted to increase the classroom interest and attract students' attention, we not only supplement and enrich the teaching content, but also greatly increase students' learning enthusiasm, and arouse their thinking after the introduction of ideological and political ideas in the end.

Finally, teaching and educating should be closely linked and never separated. While the teachers of colleges and universities impart advanced mathematics knowledge to students, they are also influencing the students' outlook on life. Therefore, a teacher is not only the imparter of knowledge, but also the guide of thought. Advanced mathematics and ideological and political education are the relationship between human body and soul for spirit and flesh can never be separated. The curriculum not only educates people, but also tells students the requirements of the times, so that the classroom can be filled with positive energy of the society. In addition, the moral cultivation of advanced mathematics teachers should also be strengthened. Teachers are the demonstrations of promoting ideological and political education in advanced mathematics course, so improving teachers' ideological and political moral accomplishment and professional accomplishment of advanced mathematics have an important impact on the cultivation of students' academic height, integrity and professional ability.

\section{Education Exploration of Mathematics Teachers in Colleges and Universities}

In the process of course teaching, advanced mathematics teachers in colleges and universities tend to attach more importance to tools while giving less curriculum content to morality cultivation, which is the weak link and loophole of advanced mathematics courses' participation in "curriculum ideology and politics". As a result, in order to solve the problem that advanced mathematics teachers in colleges and universities tend to attach more importance to tools while neglecting morality cultivation, schools should strengthen the education and training of teachers in "curriculum ideology and politics", so that teachers' teaching concepts and habits can keep pace with the times and make progress ${ }^{[6]}$. To this end, we can proceed from the

\section{following three aspects:}

(1) Advanced mathematics teachers' understanding of "curriculum ideology and politics" should be strengthened. Teachers are the demonstrations to students. Only when mathematics teachers believe the function of "curriculum ideology and politics" of advanced mathematics course in enhancing students' knowledge and ability and shaping correct values, can they have a deeper understanding of "curriculum ideology and politics" so as to understand the requirements and values of curriculum education and ultimately promote the steady increase of intrinsic demand for ideological and political education.

(2) The teaching methods of mathematics course need to be improved urgently, and the content of "curriculum ideology and politics" should be deeply excavated in combination with specialty. Mathematics teachers in colleges and universities should pay attention to starting from the characteristics of advanced mathematics in the course of teaching. On the basis of unchanged mathematics curriculum standard, by drawing lessons from the ideas and thoughts in mathematics curriculum, we should deeply excavate the inherent truth and value of mathematical thought, and organically combine with ideological and political education elements, integrating ideological and political education into classroom perfectly. We are to strictly request students to have a rigorous and logical view towards problems, foster their persistent belief in truth, meticulous attitude towards work and scientific spirit of seeking truth from facts, cultivate students to be a disciplined, honest and trustworthy person, and make their aesthetic consciousness based on the orderliness, conciseness, symmetry and unity of mathematics, so that students' sentiment can be improved.

(3) The construction plan should be designed systematically. With the aim of driving advanced mathematics teaching and ideological and political education in the same direction, starting from the reality of mathematics teaching and based on the specialty characteristics, this paper puts forward a practical, rational, efficient and reasonable construction plan, promptly pushes out new teaching content, adds new teaching means, and makes orderly and full use of existing human resources of teachers, historical and cultural resources of schools or local areas, professional celebrities resources and background resources of teaching materials, contributing to the construction of ideological and political education in advanced mathematics course.

\section{Conclusion}

Ideological and political education in higher vocational colleges is a systematic work. It is not only the work con- 
tent of ideological and political teachers and counselors, but also the teaching task that every full-time teacher should follow up. From the above, we can see that the teaching of mathematics and ideological and political education in vocational education can be integrated as a whole, go in the same direction and work together to bring into play the synergistic effect of ideological and political education and advanced mathematics course. At present, the implementation scope of "curriculum ideology and politics" in vocational mathematics is relatively small, and it is still in the exploratory stage, since mathematics teaching in most classes of colleges and universities has not yet started "curriculum ideology and politics". Therefore, it is hoped that all the advanced mathematics teachers should accelerate the transformation of teaching ideas and improve existing teaching methods, striving to improve their own ideological and political quality so as to achieve the all-round education of "curriculum ideology and politics" in mathematics course.

\section{References}

[1] Xi Jinping, Xi Jinping Emphasized at the National Conference on Ideological and Political Work in Col- leges and Universities: The Ideological and Political Work Should Run Through the Whole Process of Education and Teaching, and a New Situation for the Development of Higher Education in China should be created[N]. People's Daily.

[2] Liu Lei. Exploration of the Way to Realize Ideological and Political Education in Curriculum[J]. Journal of Guangxi College of Education, 2018(4):123-125.

[3] Gao Ming. Exploration of Ideological and Political Education in Advanced Mathematics Course[J]. Journal of Tianjin Academy of Educational Science, 2019,06(25):1102-1103.

[4] Qiu Weiguang. The Value Implication and Generating Path of Curriculum Ideology and Politics[J]. Ideological and Theoretical Education, 2017(07):122-123.

[5] Xu Ping. Reflections on "Curriculum Ideology and Politics" in Advanced Mathematics in the Cultivation of Excellent Talents[J]. Course Education Research, 2018.08(10):117-119.

[6] Zheng Yi. Thought and Practice of "Curriculum Ideology and Politics" in University Mathematics[J]. Journal of Ningbo Institute of Education, 2019(02):93-94. 